\title{
The Influence of CNT Structural Parameters on the Properties of CNT and CNT-Reinforced Epoxy
}

\author{
A. Anvari $(\mathbb{D}$ \\ Department of Mechanical and Aerospace Engineering, University of Missouri-Columbia, Columbia, Missouri, USA \\ Correspondence should be addressed to A. Anvari; aabm9@mail.missouri.edu
}

Received 10 January 2020; Revised 17 April 2020; Accepted 6 May 2020; Published 23 May 2020

Academic Editor: Antonio Viviani

Copyright (c) 2020 A. Anvari. This is an open access article distributed under the Creative Commons Attribution License, which permits unrestricted use, distribution, and reproduction in any medium, provided the original work is properly cited.

\begin{abstract}
The main objective of this research is to review and investigate the influence of carbon nanotube structure on the properties of carbon nanotube and carbon nanotube-reinforced epoxy. Carbon nanotube and carbon nanotube-reinforced epoxy are currently being frequently used in many applications such as aerospace, automotive, and electronics industries due to their excellent properties such as high tensile strength, high Young's modulus, and electrical and thermal conductivity. In this study, the obstacles to apply carbon nanotubes as fibers within the matrix have been introduced and discussed. Additionally, the epoxy properties and application have been cited, and failure mechanisms of carbon nanotube-reinforced epoxy and geometries of carbon nanotubes have been reviewed. Furthermore, with using experimental data and applying an analytical method, the effect of carbon nanotube diameter on interlaminar shear stress within the carbon nanotube-reinforced epoxy interface has been evaluated. Additionally, the effect of temperature variation on the value of interlaminar shear stress within the single-walled carbon nanotube-reinforced epoxy interface has been discussed. Finally, the influence of the number of hexagons in the unit cell on the Young's modulus of zigzag and armchair single-walled carbon nanotubes has been evaluated.
\end{abstract}

\section{Introduction}

Carbon nanotubes (CNTs) have been introduced by Lijima in 1991 for the first time [1]. Due to the excellent properties of CNT, nowadays, its application is broad in many industries such as aerospace and automotive industries. Carbon nanotubes have great mechanical properties such as high tensile strength, high Young's modulus, and a high aspect ratio which makes CNT one of the best materials for different applications. Furthermore, the electrical conductivity of $\mathrm{CNT}$ is high [2]. Hence, recently, for enhancing the knowledge regarding the CNTs, a few studies to further analyze the mechanics and forest synthesis of CNT have been published [3-6].

There are many methods to produce the CNTs such as catalyst arrays, chemical vapor deposition, electric arc discharge, sonochemistry, laser ablation, and electrolysis. It is important to know that each of these production methods will result in different CNTs with different geometries because the diameter and the length of CNTs will be different with each of these production methods. The different geom- etries of CNT can have effects on its reactivity, failure mechanism, surface interaction, and mechanical properties. Therefore, it seems that with different production methods, different CNTs with different properties can be expected [2].

Despite of the great mechanical properties of CNTs, there are a few obstacles to apply this material such as load transfer, dispersion, and alignment. For achieving higher interlaminar shear strength (ILSS) between the CNTs and matrix, high load transfer between them is required. The second challenge to apply CNTs within the polymer matrix is the problem of CNT dispersion which can cause agglomeration of CNT particles within the nanocomposite. The agglomeration of CNTs within the nanocomposite can cause stress concentration in these agglomerated areas which could result in debonding and failure. The third problem in applying CNTs is the alignment of CNTs within the polymer which does not seem very convenient due to the size of CNT which can be about several nanometers in diameter and several micrometers in length [2].

Nevertheless, the application of CNT is still broad in many industries due to its multifunctional properties such 
as thermal management, enhanced stiffness, and improved toughness [7]. There are several methods to disperse the CNTs within the matrix, uniformly. Among these methods, the most effective one is the chemical treatment with the ultrasonication process [8].

CNTs are the crystalline shape of carbon. They have a high aspect ratio due to the size of diameter which is a few nanometers and the size of the length of it which is typically about a few microns. Furthermore, they offer high flexibility and high thermal conductivity. CNTs can be in the forms of multi-walled carbon nanotubes (MWCNTs) and singlewalled carbon nanotubes (SWCNTs). One of the best materials to apply as a matrix containing CNTs is epoxy which is a thermosetting resin. Epoxy has a high corrosion and chemical resistance. Furthermore, it provides high tensile strength and high dimensional stability and adhesion. It can be applied in different industries such as aeronautics, electronics, astronautics, and other applications. As a result, it seems that CNT/epoxy can be one of the most suitable composite materials in different applications due to the excellent properties of both CNT and epoxy polymer. The only problem is to develop a method to overcome the CNTs' dispersion, alignment, and load transfer within the epoxy. The reason that CNTs tend to agglomerate is the van der Waals force between them. CNTs have high surface areas which can create high viscosity within the CNT/epoxy. This can result in bad uniformity of CNTs within the epoxy. For enhancing the load transfer between the CNTs and epoxy and improving the uniformity of CNTs within the epoxy, a method of CNT functionalization may be applied. The TEM images of functionalized or oxidized CNTs within the epoxy have shown that not only the dispersion of CNTs within the epoxy has improved but also interlocking between the CNTs and epoxy has increased which can result in higher load transfer between the CNTs and epoxy. This can result in higher ILSS within the interfaces between CNTs and epoxy which is beneficial in many applications [8].

\section{CNT Dispersions within the Epoxy}

The scanning electron microscopy (SEM) images of synthesized CNT/epoxy have revealed that applying equal and more than 1 wt.\% of CNTs into the CNT/epoxy can result in higher chance of CNTs' agglomeration within the epoxy which develops inhomogeneous dispersion within the epoxy. The reason is the increasing of viscosity which can inhibit the uniformity of CNTs within the epoxy or result in nonuniform dispersion [8].

The uniformity of dispersion of CNTs within the epoxy is of high significance as it can increase the flexural strength. As an instance, with the comparison of $1 \mathrm{wt} . \%$ pristine CNTs and $1 \mathrm{wt} . \%$ functionalized CNTs within the epoxy, the results can develop $77 \mathrm{MPa}$ and $104 \mathrm{MPa}$ flexural strength, respectively, which proves that functionalized CNTs can develop higher uniformed CNT/epoxy nanocomposites. The reason behind this enhancement of flexural strength appears to be due to the developing covalent bonds between the functionalized CNTs and the epoxy molecules which leads to the higher flexural strength of nanocomposite [8].
In Figure 1 [8], the fracture surfaces of CNT/epoxy for both agglomerated CNTs within the epoxy $(\mathrm{a}, \mathrm{b})$ and functionalized CNTs within the epoxy are shown. In Figures 1(a) and 1(b) [8], the fracture surface shows the catastrophic failure of CNT/epoxy due to the agglomerated CNTs and stress concentration in these agglomerated areas. The stress concentration in agglomerated CNTs results in macrocrack formation and with the continuous crack propagation, failure occurs. On the other hand, in the case of functionalized CNT/epoxy (Figures 1(c) and 1(d)) [8], the cracks develop on the interfaces between the CNTs and epoxy and with spreading these cracks, CNT pullout occurs which requires more energy and higher load when compared to the pristine CNT/epoxy failure. The reason that cracks form first on the interfaces could be due to the shear stress formed around the CNTs within the production process, or due to the nonuniform dispersion [8].

\section{Mechanical Properties, Geometries, and Failure Mechanism}

As it has been mentioned previously, the discovery of CNTs occurred in 1991. After the discovery of CNTs, its application started to increase due to the unique and important properties such as high strength, high modulus, high stiffness, and electrical conductivity. Compared to steel which is one of the most popular metals in different industries, CNTs offer higher Young's modulus and tensile strength. The Young's modulus of steel is about $200 \mathrm{GPa}$, while the Young's modulus of CNTs is around $1 \mathrm{TPa}$. The tensile strength of steel is about $505 \mathrm{MPa}$ while the tensile strength of CNTs is about $1163 \mathrm{GPa}$. Moreover, CNTs can be used in other applications such as energy storage devices, hydrogen storage media, and sensors [9].

CNTs are composed of graphene layers rolled to form cylinders with fullerene caps. SWCNT has only one graphene sheet while MWCNT has several graphene sheets rolled over each other with the same axis. The geometries of CNTs could be in three states: 1 armchair, 2 zig-zag, and 3 chiral. CNT thickness is $0.34 \mathrm{~nm}$ which is equal to the thickness of the graphene sheet, but the length and diameter of the CNT can vary. In Figure 2 [9], the three different geometries of CNTs are illustrated.

In order to investigate the failure mechanism of CNT/epoxy, in 2016, an analytical method has been introduced. This method divides the interfaces of CNT/epoxy into three parts. The first part is the area at which CNT and epoxy are fully bonded and the bonds are strong in containing covalent strong bonds. The second region is the area at which the CNTs and epoxy are partially bonded. It means that some of the atoms or molecules of CNT and epoxy in this area are not bonded. The third area is the surface at which no bonding exists between CNTs and epoxy. According to this analysis, the interface of CNT-reinforced epoxy close to the CNT end cap is the most vulnerable area and stress concentration and crack initiation occur in this region. After the failure occurrence at interface, the epoxy also cracks in the region close to the end cap of the CNT. The path of fracture 


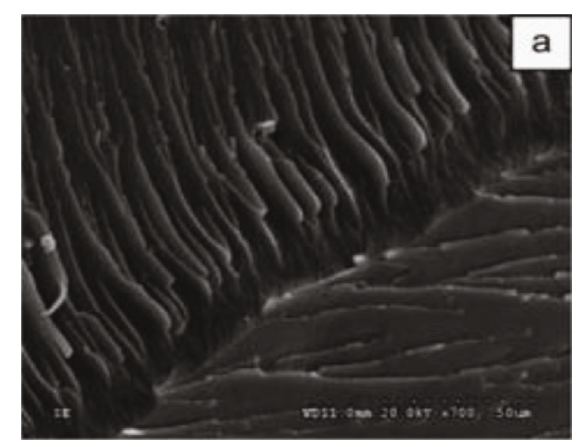

(a)

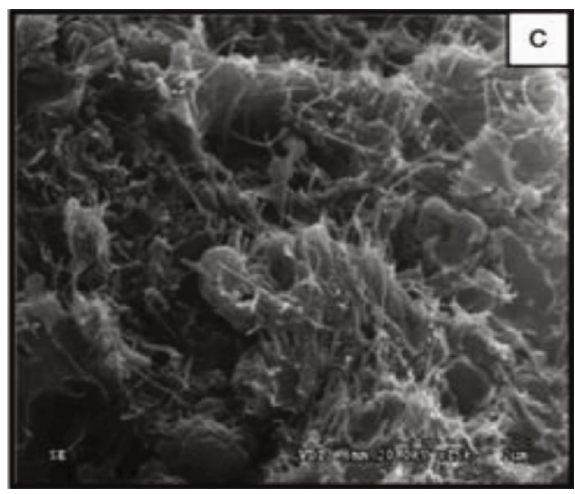

(c)

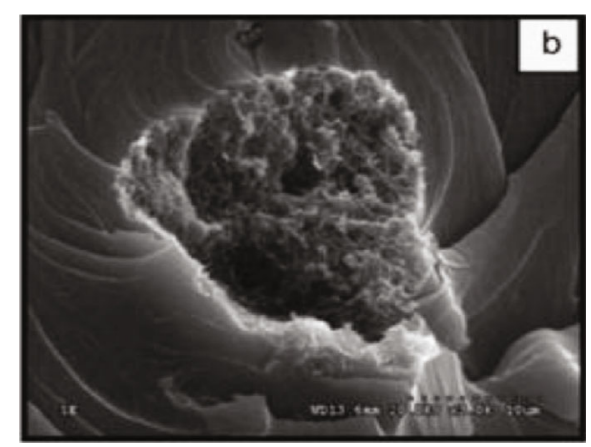

(b)

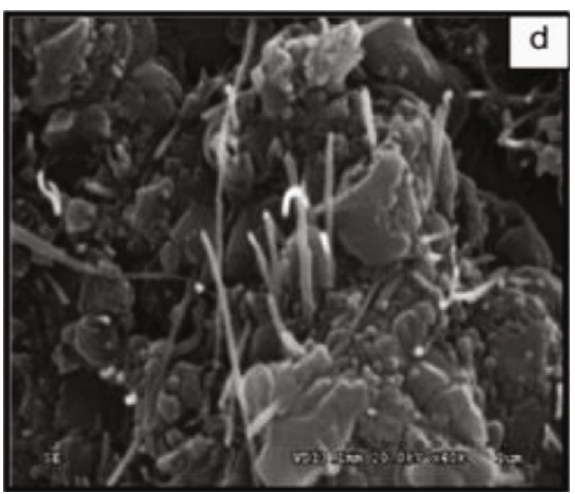

(d)

Figure 1: Fracture surface of (a,b) agglomerated CNTs within the epoxy and (c-d) functionalized CNT/epoxy composite containing 1 wt.\% functionalized CNTs [8].

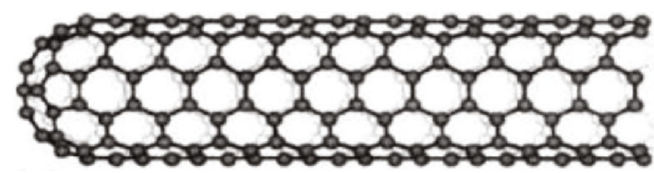

(a)
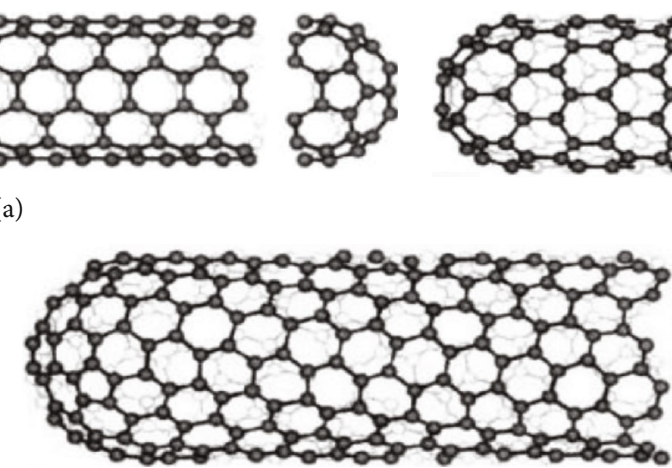

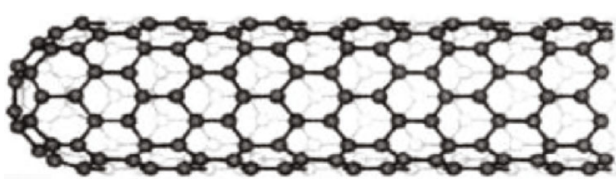

(b)
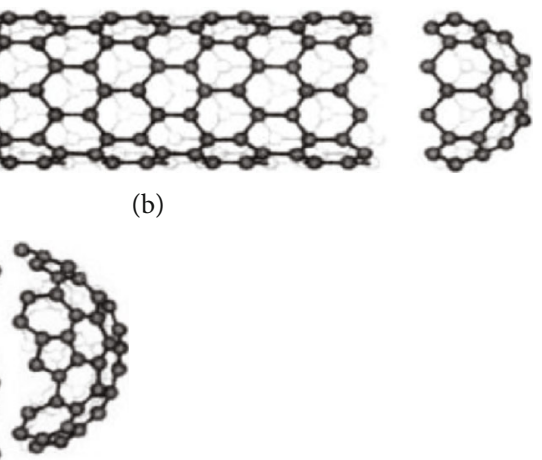

(c)

Figure 2: Different chiralities of CNTs. 1 armchair, 2 zig-zag, 3 chiral [9].

is from the epoxy crack to the failure location near the CNT cap [9].

Experiments have shown that the addition of $0.25 \mathrm{wt} . \%$ carbon nanofibers (CNF) to glass/epoxy can increase the shear strength and shear modulus by at least $18 \%$ and $34 \%$, respectively [10]. In the area of fatigue prediction, a novel model to predict the fatigue life and stiffness reduction in thermoplastics filled with two-dimensional nanoparticles has been developed by Shokrieh et al. [11]. Recent experiments have indicated that addition of $0.25 \mathrm{wt} . \% \mathrm{CNT}$ to glass/epoxy can improve the in-plane shear modulus and strength by $11 \%$ and $15 \%$, respectively [12]. Furthermore, bending fatigue experiment has shown that the addition of $0.25 \mathrm{wt} . \%$ graphene nanoplatelets to epoxy resin can improve the bending fatigue life by 27.4 -fold [13].

\section{Effect of MWCNT Diameter on Interlaminar Shear Stress of MWCNT/Epoxy}

The significant goal of this part of the study is to investigate the effect of MWCNT diameter on interlaminar shear stress (ILSs) of MWCNT/epoxy (MWCNTE). MWCNTE is one of the nanocomposite materials that is currently being used in many applications such as aerospace industry due to its 
high strength and lightweight. In this study, by applying an analytical method and using experimental data, it is attempted to evaluate the effect of MWCNT diameter on ILSs of MWCNTE. For this assessment, two kinds of MWCNTs with different diameters are chosen. The mismatches of coefficients of thermal expansion between MWCNTs and epoxy at temperature range of $-5^{\circ} \mathrm{C}$ to $70^{\circ} \mathrm{C}$ for both MWCNTs are calculated. Finally, with the results which are obtained by this assessment, ILSs of these two MWCNTE nanocomposites are compared. The results have shown that the nanocomposite which is contained with a MWCNT with a smaller diameter could offer a lower ILSs. Because MWCNTs could be manufactured in different diameter sizes, the results of this study could be used in applications dealing with thermal cycles or thermal stress to select the suitable MWCNT with the appropriate diameter within the epoxy for having the lowest ILSs.

In many industries, such as aerospace and automobile, application of composite materials has become common [14]. Additionally, in current years, it has been tried to use nanocomposites in many industries [15]. In order to fabricate nanocomposites, instead of fibers, nanofibers are used. These nanofibers could be SWCNT, MWCNT, and triplewalled carbon nanotube, etc. [16, 17]. Application of the mentioned nanofibers instead of fibers has the potential to enhance the strength of nanocomposites.

With the results which have been provided in 2018 [18] and applying the previous form of the thermal stress equation [19], a relation has been developed [18] to derive the maximum interlaminar shear stress (ILSs $s_{\max }$ ) within the unidirectional fibers/matrix composites (UFMC). This equation is indicated below.

$$
\text { ILSsmax }=(\Delta \alpha A \cdot \max ) \cdot \Delta T \cdot(\mathrm{Gmax}) .
$$

It is important to notice that in equation (1), $\Delta \alpha_{\mathrm{Amax}}$ is equal to the maximum value of "axial coefficient of thermal expansion (CTE) of epoxy $\left(\alpha_{\text {epoxy }}\right)$ minus the axial CTE of CNT $\left(\alpha_{\mathrm{CNT}}\right)$. This relation is indicated below. This equation is valid for any UFMC including SWCNTE and MWCNTE

$$
\Delta \alpha_{A \max }=\alpha_{\text {epoxy }}-\alpha_{\mathrm{CNT}} .
$$

Because $\alpha_{\text {epoxy }}$ is a positive value and the $\alpha_{\mathrm{CNT}}$ in most cases is a negative value, the amount of $\Delta \alpha$ will usually become a positive value and is indicated in Table 1.

It seems that by increasing the application of nanocomposites in different industries, analysis in order to obtain the mechanical properties of these nanocomposites exposed to different environments such as space environment is required. A great instance of this application is satellite structure that rotates around the earth. As it rotates around the earth in low earth orbit, it passes through the sun illumination and earth's shadow that are extremely hot $\left(120^{\circ} \mathrm{C}\right)$ and cold $\left(-175^{\circ} \mathrm{C}\right)$, respectively [20].

Consequently, an exact thermal analysis for nanocomposites exposed to extremely hot and cold temperatures
TABLE 1: Mismatches between the CTEs of 1.4-SWCNT and epoxy $(\Delta \alpha)$ and ILSs at a temperature range of -5 to $85^{\circ} \mathrm{C}$ within the 1.4-SWCNTE.

\begin{tabular}{lcc}
\hline \multirow{2}{*}{ Temperature $\left({ }^{\circ} \mathrm{C}\right)$} & \multicolumn{2}{c}{$1.4-$ SWCNTEC } \\
\hline-5 & $5 \alpha\left(1 /{ }^{\circ} \mathrm{C} e-5\right)$ & ILSs $(\mathrm{MPa})$ \\
0 & 6.0 & 28.4 \\
5 & 6.4 & 24.8 \\
10 & 5.7 & 20.6 \\
15 & 5.1 & 13.3 \\
20 & 4.8 & 7.30 \\
25 & 4.6 & 2.60 \\
30 & 4.6 & 1.70 \\
35 & 4.9 & 5.90 \\
40 & 5.3 & 10.6 \\
45 & 5.4 & 16.2 \\
50 & 5.6 & 21.5 \\
55 & 5.9 & 27.5 \\
60 & 6.1 & 33.8 \\
65 & 6.2 & 40.4 \\
70 & 6.4 & 46.6 \\
75 & 6.6 & 54.0 \\
80 & 6.8 & 61.6 \\
85 & 6.9 & 69.7 \\
Average & 5.7 & 76.9 \\
\hline
\end{tabular}

seems necessary. Thermal analysis could provide data to derive the ILSs of the nanocomposite. It appears that as the value of ILSs increases, the probability of interlaminar deterioration within the nanocomposite increases. ILSs is highly proportional to the mismatch of CTEs between the nanofibers and epoxy matrix. There are many studies related to the research regarding the CTEs of many fiber and epoxy materials [21, 22]. Nevertheless, it seems that there is no study regarding the effect of the MWCNT diameter on ILSs of MWCNTE.

In the presented part of the research, with using an analytical method with equation (1) and applying experimental results [16], it is attempted to investigate the effect of MWCNT diameter on the ILSs of MWCNTE. The results of this study could be very advantageous to select the best MWCNTE in cases dealing with thermal cycle or thermal stress.

4.1. Experimental Procedures. Spinnable MWCNT arrays were obtained by chemical vapor deposition using $\mathrm{C}_{2} \mathrm{H}_{2}$ and $\mathrm{FeCl}_{2}$ as the base material and the catalyst, respectively. The diameter of the MWCNTs was measured using a transmission electron microscope (TEM, JEOL JEM-2100F, Japan). A partially cured epoxy resin (B-stage epoxy) with a release paper was used as the starting material, where the epoxy resin comprised bisphenol-A-type epoxy, novolactype epoxy, and an aromatic diamine curing agent. The epoxy resin was then impregnated into the MWCNT monolithic sheet at $90^{\circ} \mathrm{C}$ for 3 min between the steel plates of a hot 
press (AS ONE AH-4015, Japan). After peeling off the release paper from the MWCNT sheet now impregnated with the epoxy resin (prepreg sheet), the prepreg sheet was cured at $130^{\circ} \mathrm{C}$ for $1.5 \mathrm{~h}$ at a pressure of $1 \mathrm{MPa}$ using the hot press, forming a film specimen [16].

4.2. Problem Formulation. In Table 2 [16], CTEs of epoxy, $25 \mathrm{~nm}$ diameter MWCNT (25-MWCNT), and $41 \mathrm{~nm}$ diameter MWCNT (41-MWCNT) within the temperature range of $-5^{\circ} \mathrm{C}$ to $70^{\circ} \mathrm{C}$ are indicated. According to equation (1), variation of CTEs between the epoxy and the MWCNT within the MWCNTE is one of the reasons to raise ILSs within the nanocomposite material. Thus, in this study, it is assumed that composites with less variation of CTEs between epoxy and MWCNT have higher ILSS. According to the results obtained in 2018 [18], degradation of ILSS within the UFMC could be the main cause of thermal fatigue failure in these nanocomposite materials. It seems important to note that relation (1) can be applied in cases where fibers are imbedded within the matrix.

In equation (1), $\Delta T$ is the temperature variation between the crack-free temperature of the CNT/epoxy and the ambient temperature. $G_{\max }$ is the maximum shear modulus between the epoxy and CNT.

4.3. Results and Discussion. In the presented section of the manuscript, thermal analysis is performed to investigate the effect of the MWCNT diameter on ILSs of MWCNTE. In order to evaluate this effect, variation of CTEs between epoxy and 25-MWCNT, and epoxy and 41-MWCNT at the temperature range of $-5^{\circ} \mathrm{C}$ to $70^{\circ} \mathrm{C}$ are calculated and indicated in Table 3 and illustrated in Figures 3 and 4. According to the data in Table 3 , at the temperature $5^{\circ} \mathrm{C}$, the mismatches of CTEs between epoxy and 25-MWCNT, and epoxy and 41-MWCNT, are $6.29 e-5\left(1 /{ }^{\circ} \mathrm{C}\right)$ and $6.90 e$ $-5\left(1 /{ }^{\circ} \mathrm{C}\right)$, respectively. These mismatches of CTEs are highest for both MWCNTEs. It means that according to equation (1), at this temperature, ILSs could be the maximum value. This phenomenon could result in higher probability of crack initiation and/or debonding between MWCNT and epoxy. This temperature that is representing the highest mismatch of CTEs between MWCNT and epoxy could be named as "critical temperature," because in this temperature, the probability of crack initiation and/or propagation could be the highest value. However, it is significant to pay attention that the comparison between the ILSs of two MWCNTEs here is based on the assumption that both 25-MWCNT and 41-MWCNT have the same value of shear modulus.

Furthermore, by analyzing Table 3 , it can be concluded that mean and maximum CTE variations between 41MWCNT and epoxy are higher than that for 25-MWCNT and epoxy. It means that ILSs between 41-MWCNT and epoxy could be higher than that between 25-MWCNT and epoxy. Due to the higher ILSs concentration within the 41MWCNTE interface in comparison with that within the 25MWCNTE, the risk of crack initiation and debonding increases within the nanofibers and epoxy interfaces.
TABLE 2: CTEs of epoxy resin, 25-MWCNT, and 41-MWCNT at temperatures from -5 to $70^{\circ} \mathrm{C}[16]$.

\begin{tabular}{lcccc}
\hline No. 1 & Temperature $\left({ }^{\circ} \mathrm{C}\right)$ & $\begin{array}{c}\text { Epoxy } \\
\text { resin }\end{array}$ & CTE $\left(1 /{ }^{\circ} \mathrm{C} e^{-5}\right)$ \\
\hline 1 & -5 & 4.60 & -1.15 & -2.00 \\
2 & 0 & 4.95 & -1.10 & -1.80 \\
3 & 5 & 5.30 & -0.99 & -1.60 \\
4 & 10 & 4.60 & -0.89 & -1.43 \\
5 & 15 & 4.00 & -0.79 & -1.30 \\
6 & 20 & 3.70 & -0.70 & -1.14 \\
7 & 25 & 3.50 & -0.61 & -1.02 \\
8 & 30 & 3.53 & -0.53 & -0.93 \\
9 & 35 & 3.80 & -0.45 & -0.85 \\
10 & 40 & 4.15 & -0.37 & -0.80 \\
11 & 45 & 4.30 & -0.31 & -0.76 \\
12 & 50 & 4.50 & -0.24 & -0.75 \\
13 & 55 & 4.70 & -0.18 & -0.75 \\
14 & 60 & 4.90 & -0.13 & -0.78 \\
15 & 65 & 5.00 & -0.08 & -0.82 \\
16 & 70 & 5.20 & -0.03 & -0.90 \\
\hline
\end{tabular}

TABLE 3: CTE differences between 25-MWCNT and epoxy and between $41-\mathrm{MWCNT}$ and epoxy $(\Delta \alpha)$ at a temperature range of $-5^{\circ} \mathrm{C}$ and $70^{\circ} \mathrm{C}$.

\begin{tabular}{lccc}
\hline \multirow{2}{*}{ No. 1 } & \multirow{2}{*}{ Temperature $\left({ }^{\circ} \mathrm{C}\right)$} & \multicolumn{2}{c}{$\Delta \alpha\left(1 /^{\circ} \mathrm{C} e^{-5}\right)$} \\
& & $\alpha_{\text {epoxy }}-\alpha_{25-M W C N T}$ & $\alpha_{\text {epoxy }}-\alpha_{41-M W C N T}$ \\
\hline 1 & -5 & 5.75 & 6.60 \\
2 & 0 & 6.05 & 6.75 \\
3 & 5 & $6.29 *$ & $6.90 *$ \\
4 & 10 & 5.49 & 6.03 \\
5 & 15 & 4.79 & 5.30 \\
6 & 20 & 4.40 & 4.84 \\
7 & 25 & 4.11 & 4.52 \\
8 & 30 & 4.06 & 4.46 \\
9 & 35 & 4.25 & 4.65 \\
10 & 40 & 4.52 & 4.95 \\
11 & 45 & 4.61 & 5.06 \\
12 & 50 & 4.74 & 5.25 \\
13 & 55 & 4.88 & 5.45 \\
14 & 60 & 5.03 & 5.68 \\
15 & 65 & 5.08 & 5.82 \\
16 & 70 & 5.23 & 6.10 \\
\hline
\end{tabular}

\section{Effect of SWCNT Diameter on Interlaminar Shear Stress of SWCNT/Epoxy}

The fundamental aim of this part of the study is to investigate the effect of the SWCNT diameter on ILSs of SWCNT/epoxy (SWCNTE). For this purpose, three SWCNTs with three different sizes of diameters are selected. Furthermore, 


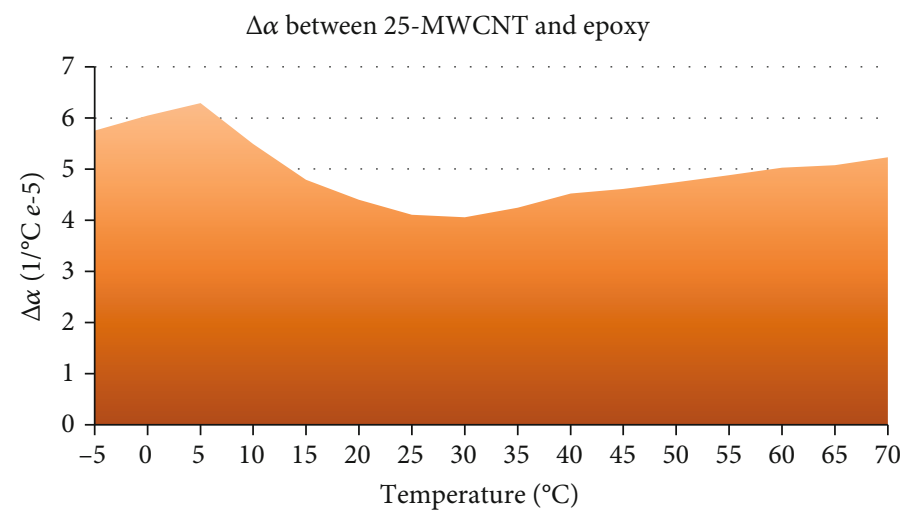

Figure 3: CTE differences between 25-MWCNT and epoxy $(\Delta \alpha)$ at a temperature range of $-5^{\circ} \mathrm{C}$ to $70^{\circ} \mathrm{C}$.

$\Delta \alpha$ between $41-\mathrm{MWCNT}$ and epoxy

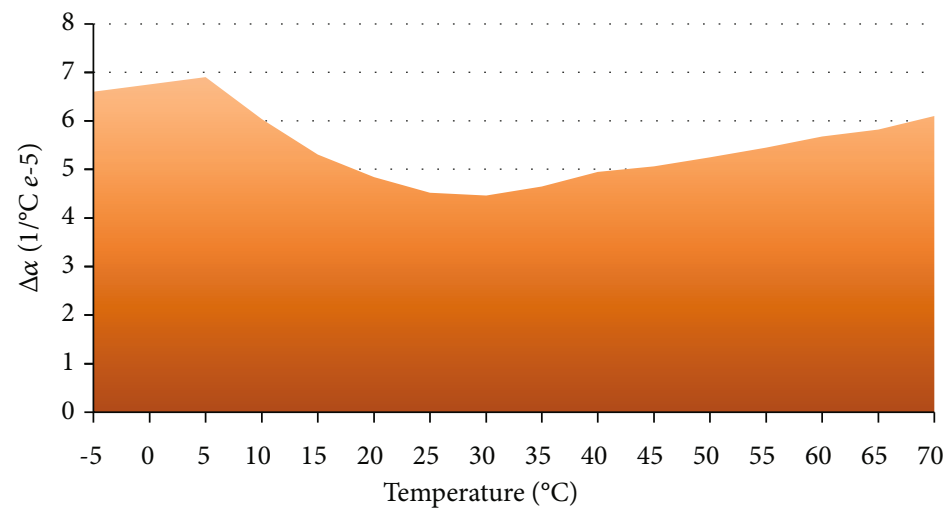

Figure 4: CTE differences between $41-\mathrm{MWCNT}$ and epoxy $(\Delta \alpha)$ at a temperature range of $-5^{\circ} \mathrm{C}$ to $70^{\circ} \mathrm{C}$.

differences of coefficients of thermal expansion between the SWCNT and epoxy for three different diameter sizes of SWCNTs at a temperature range of -5 to $85^{\circ} \mathrm{C}$ are calculated. Additionally, for these three nanocomposites, ILSs at the same temperature range are derived. Finally, based on the results obtained, ILSS of three SWCNTEs are compared. The results have shown that SWCNTE contained with SWCNT which has $13.6 \mathrm{~nm}$ diameter can offer higher ILSS due to minimum ILSs in comparison with the other two nanocomposites. The reason is less stress concentration on interface within the SWCNTE that would cause less crack initiation, propagation, and debonding on SWCNTE interface. For evaluating the ILSs within the SWCNT and epoxy interface, the same method which has been used in the previous section (section 7) has been applied in this section.

In the presented part of the research, by using the analytical method and applying experimental data [16], it is attempted to compare the ILSs within three SWCNTEs where each contains SWCNT with different sizes of diameters. The results have shown that SWCNTE with SWCNT which has the largest diameter may offer higher ILSS when compared with that for other SWCNTEs.

5.1. Experimental Procedures. Spinnable SWCNT arrays were obtained by chemical vapor deposition using $\mathrm{C}_{2} \mathrm{H}_{2}$ and $\mathrm{FeCl}_{2}$ as the base material and the catalyst, respectively. The diam- eter of the SWCNTs was measured using a transmission electron microscope (TEM, JEOL JEM-2100F, Japan). A partially cured epoxy resin (B-stage epoxy) with a release paper was used as the starting material, where the epoxy resin comprised bisphenol-A-type epoxy, novolac-type epoxy, and an aromatic diamine curing agent. The epoxy resin was then impregnated into the SWCNT monolithic sheet at $90^{\circ} \mathrm{C}$ for 3 min between the steel plates of a hot press (AS ONE AH4015, Japan). After peeling off the release paper from the SWCNT sheet now impregnated with the epoxy resin (prepreg sheet), the prepreg sheet was cured at $130^{\circ} \mathrm{C}$ for $1.5 \mathrm{~h}$ at a pressure of $1 \mathrm{MPa}$ using the hot press, forming a film specimen [16].

5.2. Problem Formulation. In this part of the manuscript, the method which has been applied in the previous section of the article for evaluating the ILSS of MWCNTE has been used for SWCNTE. Therefore, equation (1) has been used to calculate the ILSs within the SWCNTE interface.

In Table 4, CTEs and shear modulus of SWCNTs with 1.4 (1.4-SWCNT), 7 (7-SWCNT), and $13.6 \mathrm{~nm}$ (13.6-SWCNT) diameters and epoxy at a temperature range of -5 to $85^{\circ} \mathrm{C}$ are indicated. With the presented data in Table 4 and using equation (1), in Results and Discussion of the manuscript, ILSS of SWCNTEs contained with SWCNTs with three different diameters are compared. 
TABLE 4: CTEs and shear modulus of 1.4-SWCNT, 7-SWCNT, 13.6 SWCNT, and epoxy at a temperature range of -5 to $85^{\circ} \mathrm{C}$.

\begin{tabular}{|c|c|c|c|c|c|c|c|c|}
\hline \multirow[b]{2}{*}{$\begin{array}{l}\text { Temperature } \\
\left({ }^{\circ} \mathrm{C}\right)\end{array}$} & \multicolumn{2}{|c|}{ 1.4-SWCNT } & \multicolumn{2}{|c|}{ 7-SWCNT } & \multicolumn{2}{|c|}{ 13.6-SWCNT } & \multicolumn{2}{|c|}{ Epoxy } \\
\hline & $\begin{array}{c}\mathrm{CTE}\left(1 / /^{\circ} \mathrm{C}\right. \\
e-5)[16]\end{array}$ & $\begin{array}{l}\text { Shear modulus } \\
\text { (GPa) [17] }\end{array}$ & $\begin{array}{c}\mathrm{CTE}\left(1 /{ }^{\circ} \mathrm{C}\right. \\
e-5)[16]\end{array}$ & $\begin{array}{c}\text { Shear modulus } \\
(\mathrm{GPa})[17]\end{array}$ & $\begin{array}{c}\mathrm{CTE}\left(1 /{ }^{\circ} \mathrm{C}\right. \\
e-5)[16]\end{array}$ & $\begin{array}{l}\text { Shear modulus } \\
\text { (GPa) [17] }\end{array}$ & $\begin{array}{c}\mathrm{CTE}\left(1 /^{\circ} \mathrm{C}\right. \\
e-5)[16]\end{array}$ & $\begin{array}{l}\text { Shear modulus } \\
(\mathrm{GPa})[23]\end{array}$ \\
\hline-5 & -1.04 & 18 & -0.74 & 5.2 & -1.5 & 3.1 & 4.60 & 1.59 \\
\hline 0 & -1.05 & 18 & -0.75 & 5.2 & -1.5 & 3.1 & 4.95 & 1.59 \\
\hline 5 & -1.06 & 18 & -0.76 & 5.2 & -1.5 & 3.1 & 5.30 & 1.59 \\
\hline 10 & -1.07 & 18 & -0.76 & 5.2 & -1.6 & 3.1 & 4.60 & 1.59 \\
\hline 15 & -1.08 & 18 & -0.77 & 5.2 & -1.6 & 3.1 & 4.00 & 1.59 \\
\hline 20 & -1.10 & 18 & -0.78 & 5.2 & -1.6 & 3.1 & 3.70 & 1.59 \\
\hline 25 & -1.11 & 18 & -0.78 & 5.2 & -1.6 & 3.1 & 3.50 & 1.59 \\
\hline 30 & -1.12 & 18 & -0.79 & 5.2 & -1.7 & 3.1 & 3.53 & 1.59 \\
\hline 35 & -1.12 & 18 & -0.79 & 5.2 & -1.7 & 3.1 & 3.80 & 1.59 \\
\hline 40 & -1.13 & 18 & -0.79 & 5.2 & -1.7 & 3.1 & 4.15 & 1.59 \\
\hline 45 & -1.14 & 18 & -0.80 & 5.2 & -1.7 & 3.1 & 4.30 & 1.59 \\
\hline 50 & -1.15 & 18 & -0.80 & 5.2 & -1.7 & 3.1 & 4.50 & 1.59 \\
\hline 55 & -1.16 & 18 & -0.80 & 5.2 & -1.7 & 3.1 & 4.70 & 1.59 \\
\hline 60 & -1.16 & 18 & -0.80 & 5.2 & -1.7 & 3.1 & 4.90 & 1.59 \\
\hline 65 & -1.17 & 18 & -0.80 & 5.2 & -1.8 & 3.1 & 5.00 & 1.59 \\
\hline 70 & -1.18 & 18 & -0.80 & 5.2 & -1.8 & 3.1 & 5.20 & 1.59 \\
\hline 75 & -1.18 & 18 & -0.80 & 5.2 & -1.8 & 3.1 & 5.40 & 1.59 \\
\hline 80 & -1.19 & 18 & -0.80 & 5.2 & -1.8 & 3.1 & 5.60 & 1.59 \\
\hline 85 & -1.19 & 18 & -0.80 & 5.2 & -1.8 & 3.1 & 5.70 & 1.59 \\
\hline
\end{tabular}

5.3. Results and Discussion. In Tables 1-6, all the results from the thermal analysis (equation (1)) of three SWCNTEs are indicated. Furthermore, in Figures 5-10, all the results obtained by employing equation (1) and data in Table 4 are shown.

According to the following results, average and maximum differences of CTEs between 13.6-SWCNT and epoxy are higher than those for between 1.4-SWCNT and epoxy, and between 7-SWCNT and epoxy. On the other hand, maximum and average ILSs within 1.4-SWCNTE are higher than those within 7-SWCNTE and 13.6-SWCNTE. According to these results, because as ILSs increases, the ILSS decreases, it appears that ILSS of 13.6-SWCNTE and 1.4SWCNTE are highest and lowest, respectively. Thus, it seems that thermal cycle numbers to failure of 7-SWCNTE is between the thermal cycle numbers to failure of 13.6SWCNTE and 1.4-SWCNTE. As a result, it appears that as the diameter size of SWCNT increases, ILSS increases. These results can contribute to select the best SWCNTE in case of having maximum thermal fatigue life in environments dealing with thermal cycles.

Although the CTE mismatches between 13.6-SWCNT and epoxy are higher than those for between 1.4-SWCNT and epoxy, ILSs is higher for 1.4-SWCNTE. The reason is due to the higher shear modulus of 1.4-SWCNT $(18 \mathrm{GPa})$ [17] in comparison with that for 13.6-SWCNT $(3.1 \mathrm{GPa})$ [17], because according to equation (1), for determining ILSs, $\Delta \alpha$ is multiplied by $\Delta T$ and $G$. Thus, because $G$ is very high for 1.4-SWCNT in comparison with that for 13.6-SWCNT, ILSs is higher for 1.4-SWCNTE, although it has a lower $\Delta \alpha$ between 1.4-SWCNT and epoxy.
TABle 5: Mismatches between the CTEs of 7-SWCNT and epoxy $(\Delta \alpha)$ and ILSs at the temperature range of -5 to $85^{\circ} \mathrm{C}$ within the 7-SWCNTE.

\begin{tabular}{lcc}
\hline \multirow{2}{*}{ Temperature $\left({ }^{\circ} \mathrm{C}\right)$} & \multicolumn{2}{c}{$7-$ SWCNTEC } \\
\hline-5 & 5.3 & ILSs $(\mathrm{MPa})$ \\
0 & 5.7 & 7.80 \\
5 & 6.1 & 6.80 \\
10 & 5.4 & 5.70 \\
15 & 4.8 & 3.60 \\
20 & 4.5 & 2.00 \\
25 & 4.3 & 0.70 \\
30 & 4.3 & 0.50 \\
35 & 4.6 & 1.60 \\
40 & 4.9 & 2.90 \\
45 & 5.1 & 4.40 \\
50 & 5.3 & 5.80 \\
55 & 5.5 & 7.40 \\
60 & 5.7 & 9.20 \\
65 & 5.8 & 11.0 \\
70 & 6.0 & 12.7 \\
75 & 6.2 & 14.7 \\
80 & 6.4 & 16.8 \\
85 & 6.5 & 19.0 \\
Average & 5.4 & 21.0 \\
\hline
\end{tabular}


TABLE 6: Mismatches between the CTEs of 13.6-SWCNT and epoxy $(\Delta \alpha)$, and ILSs at the temperature range of -5 to $85^{\circ} \mathrm{C}$ within the 13.6-SWCNTE.

\begin{tabular}{lcc}
\hline \multirow{2}{*}{ Temperature $\left({ }^{\circ} \mathrm{C}\right)$} & \multicolumn{2}{c}{$13.6-\mathrm{SWCNTE}$} \\
\hline-5 & 6.1 & ILSs $(\mathrm{MPa})$ \\
0 & 6.4 & 5.30 \\
5 & 6.8 & 4.60 \\
10 & 6.2 & 3.80 \\
15 & 5.6 & 2.50 \\
20 & 5.3 & 1.40 \\
25 & 5.1 & 0.50 \\
30 & 5.2 & 0.30 \\
35 & 5.5 & 1.10 \\
40 & 5.8 & 2.00 \\
45 & 6.0 & 3.10 \\
50 & 6.2 & 4.10 \\
55 & 6.4 & 5.20 \\
60 & 6.6 & 6.30 \\
65 & 6.8 & 7.60 \\
70 & 7.0 & 8.90 \\
75 & 7.2 & 10.2 \\
80 & 7.4 & 11.6 \\
85 & 7.5 & 13.1 \\
Average & 6.3 & 14.4 \\
\hline & & 5.60 \\
\hline
\end{tabular}

It seems important to mention that deterioration and debonding within the nanofiber and matrix interface is due to the reverse behavior between the nanofiber and epoxy. This reverse behavior is the result of opposite values of CTEs between the SWCNT and epoxy, or MWCNT and epoxy. Due to the opposite values of CTEs between the nanofibers and matrix, while the MWCNTE or SWCNTE is cooling with respect to crack-free temperature, epoxy is contracting while MWCNT or SWCNT is expanding in the axial direction. On the other hand, while MWCNTE or SWCNTE is heating, epoxy is expanding, while MWCNT or SWCNT is contracting. This reverse behavior has the potential to induce deterioration and debonding within the SWCNTE or MWCNTE interfaces between the nanofibers and matrix.

The deterioration within the SWCNTE and MWCNTE interface could cause crack initiation and/or propagation within these areas. In the cases dealing with thermal cycles, this reverse behavior between the epoxy and MWCNT or SWCNT repeats over and over. Therefore, higher degradation on interface between the nanofiber and matrix can be expected.

For the effect of shear modulus on ILSs, it should be mentioned here that within $-5^{\circ} \mathrm{C}$ to $85^{\circ} \mathrm{C}$, the shear modulus would have a constant value or approximately a constant value. Therefore, it is not expected to have variational effect on ILSs.

As it is mentioned before, it appears that, the higher the ILSs, the lower the thermal fatigue life becomes. The reason is because higher ILSs can cause stress concentration on fibers and matrix interfaces. Consequently, it has a potential to induce crack initiation, propagation, and debonding within the fibers and matrix interfaces.

In the presented part of the research, by applying the analytical method and employing experimental data [16], the effect of the SWCNT diameter on ILSs of SWCNTE is investigated. For this purpose, three SWCNTs with three sizes of diameters were selected: SWCNTs with 1.4, 7, and $13.6 \mathrm{~nm}$ diameters. After analyzing the values of ILSs for these nanocomposites with nanofibers with different diameters, it has been determined that 1.4-SWCNTE and 13.6SWCNTE have the highest and lowest ILSs, respectively. It means that due to the less ILSs and, consequently, less stress concentration and crack propagation within the 13.6SWCNTE, ILSS within this nanocomposite can be higher in comparison with the other two nanocomposites. Based on the results obtained by this procedure, it appears that, the larger the diameter of SWCNT, the higher the ILSS and thermal fatigue life becomes.

\section{The Effect of Structural Parameters on the Properties of Zig-zag and Armchair Carbon Nanotubes}

Chirality is one of the structural parameters which has the potential to affect the CNT properties. Within zig-zag SWCNT, chiral angle $(\theta)$ is equal to zero, while within armchair SWCNT, $\theta$ is equal to $30^{\circ}$. If $0^{\circ}<\theta<30^{\circ}$, SWCNT is a chiral nanotube. Chirality of CNT cannot influence its strain-stress characteristics within the elastic zone but can influence its characteristics within the plastic zone. The distance between the carbon atoms within the CNT structure is $0.142 \mathrm{~nm}$. Based on the reported results which are obtained from the experiments, zig-zag CNT is capable to withstand higher tensile stress along its tube axis when compared to armchair and chiral CNTs [24].

Zig-zag, armchair, and chiral CNTs have about $1.0 \mathrm{TPa}$ Young's modulus. Additionally, the maximum tensile strength of all CNTs is equal to $0.10 \mathrm{TPa}$. Furthermore, all CNTs can elongate in the axial direction with a strain higher than 0.2 [24].

When SWCNTs are exposed to mechanical loading, the failure mode could be in the form of brittle fracture. Furthermore, while SWCNTs are subjected to high temperatures, their fracture resistance decreases, significantly. Nevertheless, at low temperatures, SWCNTs can fail in the form of brittle fracture. In the case of applying zig-zag SWCNT, the chance of failure in the form of brittle fracture at low temperatures is higher. Further analyses have shown that brittle fracture in zig-zag SWCNT is the consequence of breaking atomic bonds between the carbon atoms in a short period of time. However, longer nanotubes could exhibit higher fracture resistance when they are compared to shorter tubes [25].

Investigations have shown that structural defects within the CNT could exist in the shape of pentagon-heptagon carbon atom cell. Additionally, zig-zag SWCNTs are inclined to fracture at high strain and low temperatures. Furthermore, zig-zag SWCNTs are more likely to fracture under the 


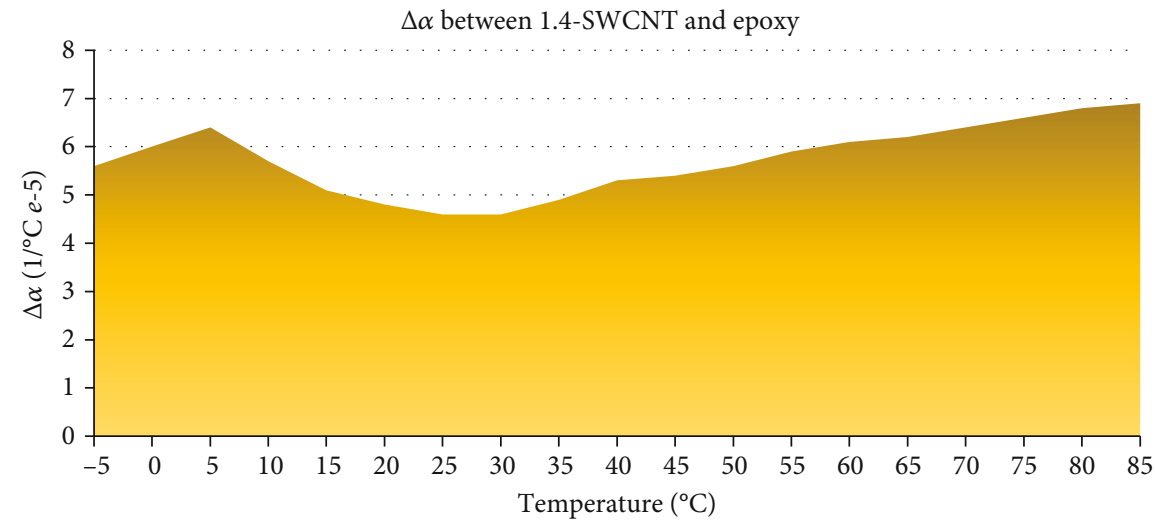

FIgURE 5: Mismatches between the CTEs of $1.4-\mathrm{SWCNT}$ and epoxy $(\Delta \alpha)$ at the temperature range of -5 to $85^{\circ} \mathrm{C}$ within the $1.4-\mathrm{SWCNTE}$.

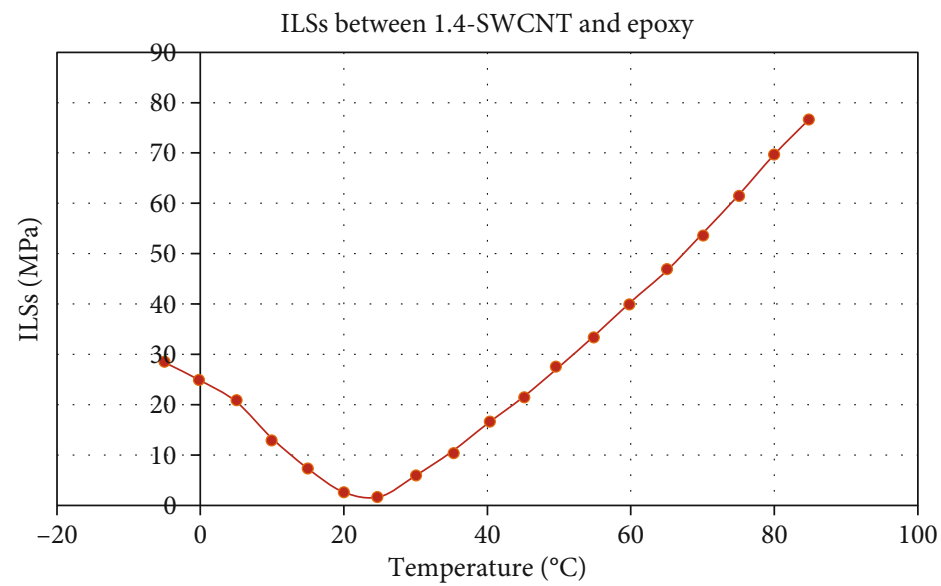

FIGURE 6: ILSs within the interface of 1.4-SWCNT and epoxy at the temperature range of -5 to $85^{\circ} \mathrm{C}$ within the $1.4-\mathrm{SWCNTE}$.

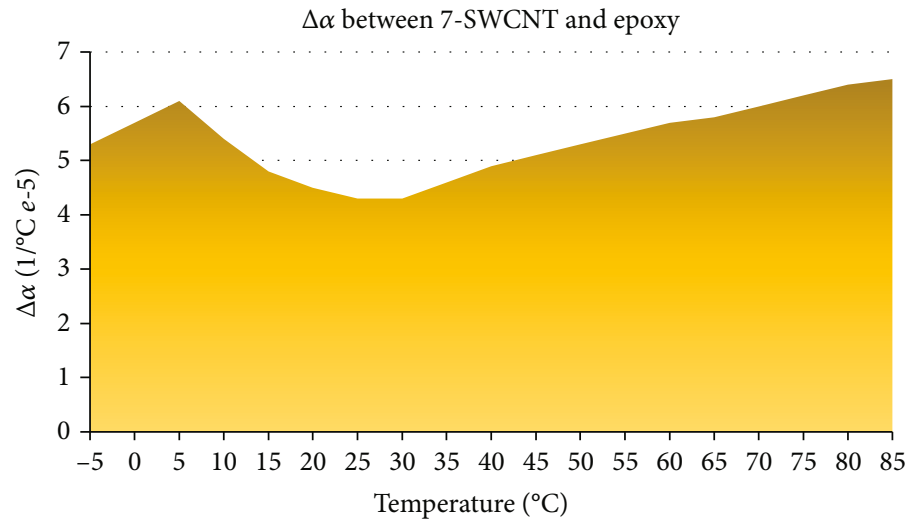

Figure 7: Mismatches between the CTEs of 7-SWCNT and epoxy $(\Delta \alpha)$ at the temperature range of -5 to $85^{\circ} \mathrm{C}$ within the $7-\mathrm{SWCNTE}$.

compressive strain rather than the tensile strain. High compressive strain along the zig-zag SWCNT axis could cause permanent deformation in the tube axial direction. In cases dealing with compressive fatigue, these permanent deformations could result in significant loss of strength and, consequently, buckling along the nanotube structure axis [26].

The SWCNT diameter is normally within the range of a few nanometers, and its length is typically larger than a micrometer. SWCNTs are identified by employing a chiral vector. The chiral vector contains two integers $(n, m)$ which could describe the SWCNT chirality. For armchair nanotubes, $n$ is equal to $m$, and for zig-zag nanotubes, $m$ is equal to zero. All other combinations of $n$ and $m$ would describe a chiral SWCNT [27].

The density functional theory (DFT) and atomistic approach could be used to calculate the Young's modulus 


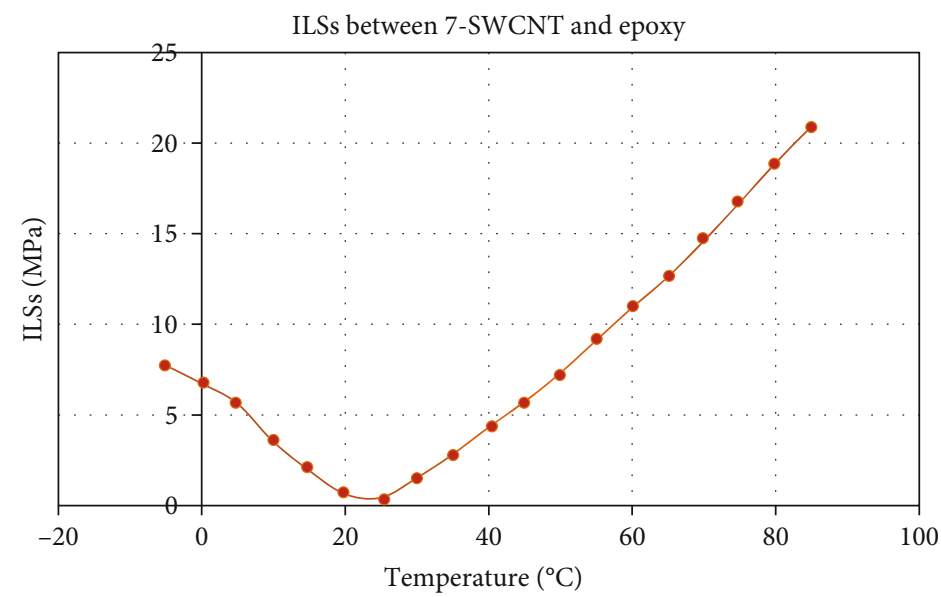

FIGURE 8: ILSs within the interface between the 7-SWCNT and epoxy at the temperature range of -5 to $85^{\circ} \mathrm{C}$ within the 7-SWCNTE.

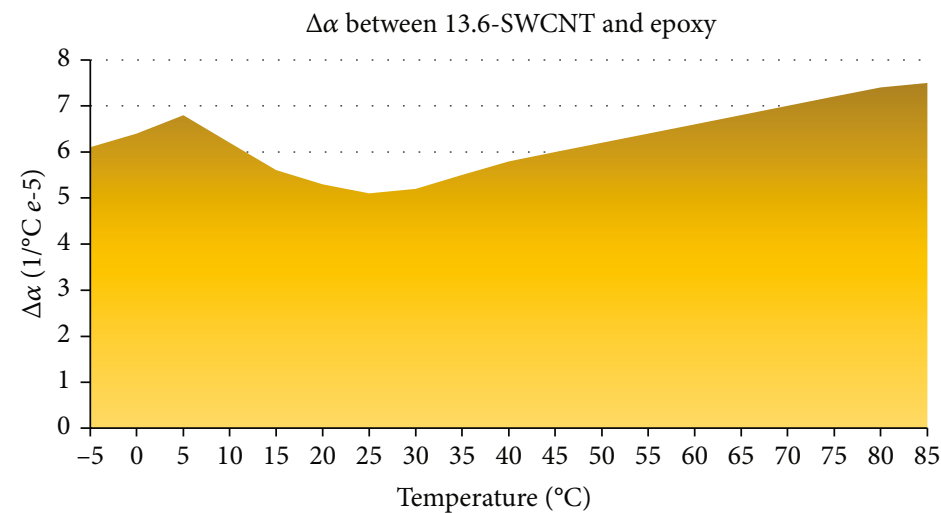

FIGURE 9: Mismatches between the CTEs of 13.6-SWCNT and epoxy $(\Delta \alpha)$ at the temperature range of -5 to $85^{\circ} \mathrm{C}$ within the 13.6 -SWCNTE.

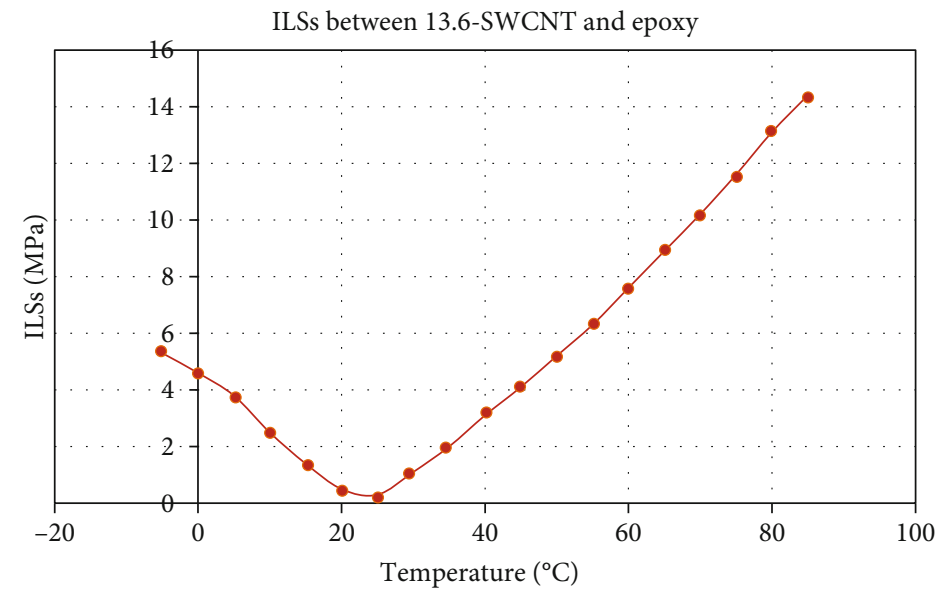

FIGURE 10: ILSs within the interface between the 13.6-SWCNT and epoxy at the temperature range of -5 to $85^{\circ} \mathrm{C}$ within the 13.6 -SWCNTE.

of SWCNTs. SWCNTs are made from carbon atoms which are bonded with hexagonal pattern. In SWCNT structure, each carbon atom is bonded to three carbon atoms [28].

Continuum mechanics and molecular dynamics (MD) numerical approaches could be used to simulate the CNT structure. Nonlinear spring modeling could be applied to simulate the C-C bond stretch in CNT structure. CNT geometry represents a frame-like structure in which carbon atoms are connected with covalent bonds. Covalent bonds between carbon atoms could be simulated as load-bearing beams. The CNT structure could determine its Young's modulus value. Shear modulus of CNT would increase with increasing its 
chiral angle. Furthermore, the increment of the chiral angle increases the CNT tensile and bending rigidity [29].

The size of the diameter and length of CNT could influence the value of its elastic moduli. The distance between the SWCNT cylinders within the MWCNT is equal to $0.34 \mathrm{~nm}$. The interaction between the SWCNTs within the MWCNT is through the van der Waals forces. The main cause of failure in CNTs could be due to buckling under compressive force. The value of Young's modulus along the CNT axis is very high, while this value is low across the CNT radial direction. The diameter of CNT could vary from 1 to $100 \mathrm{~nm}$. $\mathrm{CNT}$ is among the good thermal conductors along its axial axis. CNT is stable up to $750^{\circ} \mathrm{C}$ in air and $2800^{\circ} \mathrm{C}$ in vacuum conditions. Due to the high stiffness of CNT, it could be used to make bullet-proof clothing [30].

6.1. Interlaminar Shear Stress as a Function of Temperature. In the section 5 , it has been proved that ILSs within the SWCNTE interface can change as the temperature changes. At temperatures around the ambient temperature, this variation is low because it cannot have an effect on the value of shear modulus and the change is due to the alteration of the temperature and CTE values of SWCNT and epoxy. These effects are indicated in equation (1). However, at extreme low and high temperatures, the influence of temperature on the value of ILSs can be high. The reason is at very high and low temperatures, the value of shear modulus could change. Furthermore, the values of CTEs for both CNT and epoxy can undergo a large amount of alterations. Therefore, a high fluctuation within the value of ILSs can be expected.

According to the results which have been obtained by Kahaly and Waghmare in 2008 [27], the value of CTE for $(7,0)$ zig-zag SWCNT can increase up to $900 \%$ from room temperature to $1800 \mathrm{~K}$. These results can contribute to calculate the ILSs as a function of temperature within the zig-zag SWCNTE interface. The extremely high temperature exists in the propulsion systems and on the exterior surface of spacecrafts during the reentry to earth. As a result of this thermal analysis [27], the CTE of $(7,0)$ zig-zag SWCNT in axial direction as a function of temperature $\left(\alpha(T)_{\text {SWCNT }}\right)$, between 0 and 400 Kelvin, can be expressed with the following relation:

For $0 \mathrm{~K} \leq T<400 \mathrm{~K}$,

$$
\alpha(T)_{\mathrm{SWCNT}}=(3.75 e-12) * T 2-(1.25 e-9) * T
$$

Furthermore, the $\alpha(T)_{\text {SWCNT }}$ for temperatures between 400 and 1800 Kelvin can be expressed with the following relation:

$$
\begin{aligned}
\text { For } 400 \mathrm{~K} \leq T \leq 1800 \mathrm{~K} \\
\begin{aligned}
\alpha(T)_{\mathrm{SWCNT}}= & (-6.2 e-13) * T 2+(2.006 e-9) * T \\
& -(6.032 e-7)
\end{aligned}
\end{aligned}
$$

Consequently, with the substitution of relations (3) and (4) in equations (1), (5), and (6), ILSs are developed and shown below. Equations (5) and (6) can express the ILSs
TABLE 7: Diameter, number of hexagons in unit cell, and axial Young's modulus of zig-zag SWCNTs.

\begin{tabular}{lcccc}
\hline No. & $\begin{array}{c}\text { Type of zig-zag } \\
\text { SWCNT }\end{array}$ & $\begin{array}{c}\text { Diameter } \\
(\mathrm{nm})\end{array}$ & $\begin{array}{c}\text { Number of } \\
\text { hexagons in } \\
\text { unit cell (N) }\end{array}$ & $\begin{array}{c}\text { SWCNT } \\
\text { axial Young's } \\
\text { modulus (TPa) }\end{array}$ \\
\hline 1 & $(12,0)$ & 0.94 & 24 & $0.9700[29]$ \\
2 & $(15,0)$ & 1.17 & 30 & $1.0030[29]$ \\
3 & $(18,0)$ & 1.41 & 36 & $0.9997[29]$ \\
4 & $(28,0)$ & 2.19 & 56 & $1.1550[25]$ \\
5 & $(35,0)$ & 2.74 & 70 & $1.1750[25]$ \\
\hline
\end{tabular}

TABle 8: Diameter, number of hexagons in unit cell, and axial Young's modulus of armchair SWCNTs.

\begin{tabular}{lcccc}
\hline No. & $\begin{array}{c}\text { Type of } \\
\text { armchair } \\
\text { SWCNT }\end{array}$ & $\begin{array}{c}\text { Diameter } \\
(\mathrm{nm})\end{array}$ & $\begin{array}{c}\text { Number of } \\
\text { hexagons in } \\
\text { unit cell }(\mathrm{N})\end{array}$ & $\begin{array}{c}\text { SWCNT axial } \\
\text { Young's modulus } \\
(\mathrm{TPa})[29]\end{array}$ \\
\hline 1 & $(12,12)$ & 1.627 & 24 & 0.9300 \\
2 & $(15,15)$ & 2.034 & 30 & 0.9980 \\
3 & $(18,18)$ & 2.441 & 36 & 1.0003 \\
\hline
\end{tabular}

for the temperature range between 0 and 400 Kelvin, and 400 and 1800 Kelvin, respectively.

$$
\begin{aligned}
\operatorname{ILSs}(T)= & G(T)_{\mathrm{SWCNT}} \bullet|(T-296.15)| \bullet \mid\left(\alpha(T)_{\text {epoxy }}\right. \\
& -(3.75 e-12) * T 2+(1.25 e-9) * T) \mid, \\
\operatorname{ILSs}(T)= & G(T)_{\operatorname{SWCNT}} \bullet|(T-296.15)| \bullet \mid\left(\alpha(T)_{\text {epoxy }}+(6.2 e\right. \\
& -13) * T 2-(2.006 e-9) * T+(6.032 e-7)) \mid .
\end{aligned}
$$

As it is indicated in equations (5) and (6), ILSs is a function of temperature because the huge temperature fluctuation can change the values of CTEs of the $(7,0)$ zig-zag SWCNT, and epoxy. Furthermore, with the large alteration in the temperature, the value of SWCNT shear modulus, $G(T)_{\text {SWCNT }}$, would change. Therefore, all the parameters in the equations (5) and (6) are temperature dependent. Please note that the temperature $T$ in equations (5) and (6) is according to the Kelvin unit, and the temperature 296.15 in equations (5) and (6) is the ambient temperature based on the Kelvin unit. Additionally, $\alpha(T)_{\text {epoxy }}$ is the epoxy CTE as a function of temperature.

6.2. The Effect of Number of Hexagons in Unit Cell on SWCNT Young's Modulus. The purpose of the concept of the unit cell within the SWCNT is to classify the different symmetries in nanotubes. The unit cell is defined as a SWCNT section which is the composition of vectors that characterize and describe the spiral symmetry of the SWCNT [31]. In Figure 2 [9], it is illustrated that SWCNTs are composed of hexagons. The nodes of hexagons within the SWCNT structure are carbon atoms, and the lines between 


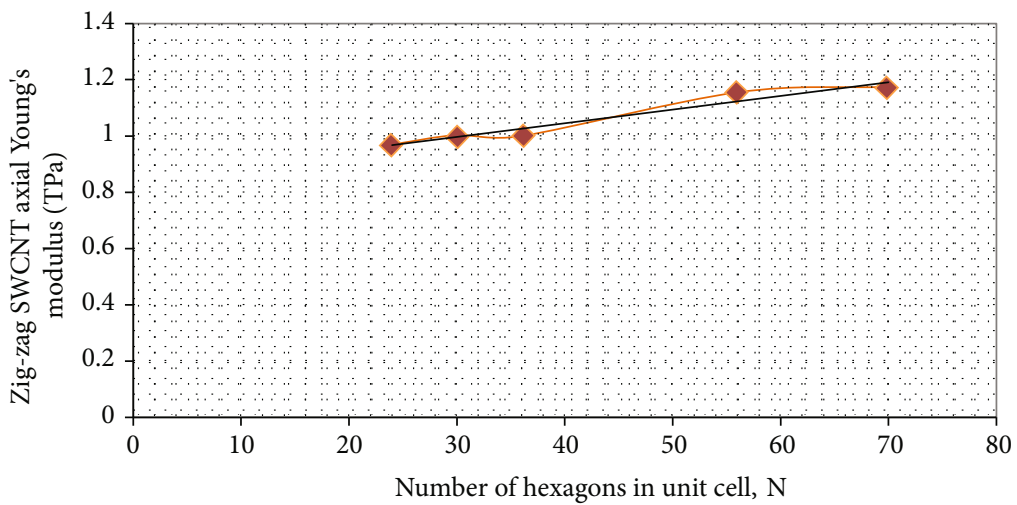

FIgURE 11: The influence of the number of hexagons in unit cell on zig-zag SWCNT axial Young's modulus.

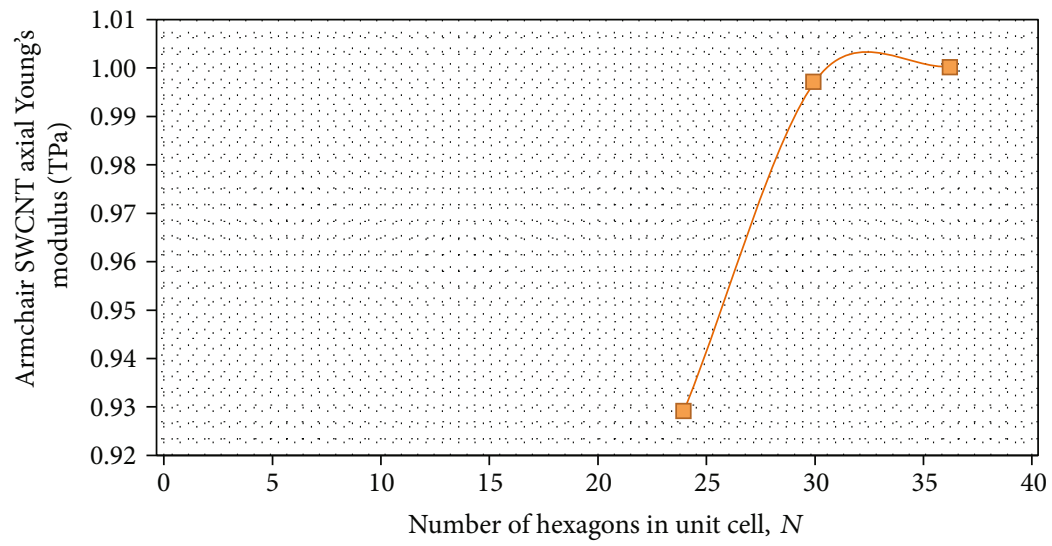

FIGURE 12: The influence of the number of hexagons in unit cell on armchair SWCNT axial Young's modulus.

the carbon atoms represent the covalent bonds between them. As it is shown in Figure 2 [9], each carbon atom is connected to three carbon atoms with covalent bonds. The goal in this part of the research is to investigate the influence of the number of hexagons in a unit cell on SWCNT axial Young's modulus.

For investigating the effect of the number of hexagons in unit cell on the axial Young's modulus of SWCNT, the following relations are used, where $d$ is the nanotube diameter, $l_{\mathrm{B}}=$ $0.142 \mathrm{~nm}$, is the length of interatomic spacing between the carbon atoms, $n$ and $m$ are the chirality vector indices, GCD is the abbreviation of greatest common divisor, and $N$ is the number of hexagons in the unit cell within the SWCNT structure [31].

$$
d=\frac{a}{\pi}(n 2+n m+m 2) \frac{1}{2},
$$

for zig-zag SWCNT, $m=0$, as a result

$$
d=\frac{a}{\pi} n
$$

Furthermore, for any SWCNT,

$$
\begin{aligned}
a & =\sqrt{3} * l \\
d R & =\operatorname{GCD}(2 n+m, 2 m+n) .
\end{aligned}
$$

For zig-zag SWCNT, $m=0$, therefore,

$$
\mathrm{dR}=\mathrm{GCD}(2 n, n)
$$

and for any SWCNT

$$
N=\left[\frac{(2(n 2+m 2+n m))}{\mathrm{dR}}\right]
$$

For zig-zag SWCNT, $m=0$, consequently,

$$
N=\left[\frac{(2(\mathrm{n} 2))}{\mathrm{dR}}\right] \text {. }
$$

With using the relations (7) to (13) [31], the number of hexagons in the unit cell of zig-zag and armchair SWCNTs is calculated and indicated in the following tables. The axial Young's modulus of $(12,0),(15,0),(18,0),(12,12),(15$, $15)$, and $(18,18)$ SWCNTs are derived by Zakeri and Shayanmehr in 2013 [29]. Furthermore, the axial Young's modulus of $(28,0)$ and $(35,0)$ SWCNTs are derived by Lu and Bhattacharya in 2006 [25]. Therefore, after the calculation of the number of hexagons in the unit cell within the SWCNTs which are mentioned above, the influence of the number of hexagons in unit cell on the axial Young's 
modulus of zigzag and armchair SWCNTs is indicated in Tables 7 and 8 and Figures 11 and 12, respectively.

\section{Summary and Conclusions}

The research topics related to CNT, epoxy, and CNT/epoxy are very broad, and in this study, only the most important topics have been covered. It seems that the topics related to the mechanical properties and damage mechanism are the most significant topics which in this study, also, it has been tried to cover them as well.

The results of thermal analyses in Sections 4 and 5 have indicated that as the diameter of MWCNT increases, ILSs value within the MWCNTE interface increases. On the other hand, as the diameter of SWCNT increases, ILSs within the SWCNTE interface decreases. The results in Section 6.1 have shown that ILSs within the SWCNTE can vary as the temperature changes. Therefore, ILSs is a function of temperature. Furthermore, based on the results which are obtained from Section 6.2, by increasing the number of hexagons in unit cell, axial Young's modulus of both zig-zag and armchair SWCNTs would increase. Additionally, the increment of axial Young's modulus of zig-zag SWCNT has an approximately linear relation with increasing the number of hexagons in unit cell.

\section{Data Availability}

The data which have been used to write this manuscript are provided from the list of references below.

\section{Conflicts of Interest}

The author declares that they have no conflicts of interest.

\section{Acknowledgments}

Part of the funding of this research has been provided by Professor Sanjeev Khanna, faculty member of the Mechanical and Aerospace Engineering Department in University of Missouri-Columbia. Therefore, I would like to thank him for his support.

\section{References}

[1] S. Iijima, "Helical microtubules of graphitic carbon," Nature, vol. 354, no. 6348, pp. 56-58, 1991.

[2] T. R. Frømyr, F. K. Hansen, and T. Olsen, "The optimum dispersion of carbon nanotubes for epoxy nanocomposites: evolution of the particle size distribution by ultrasonic treatment," Journal of Nanotechnology, vol. 2012, Article ID 545930, 14 pages, 2012.

[3] J. Brown, T. Hajilounezhad, N. T. Dee, S. Kim, A. J. Hart, and M. R. Maschmann, "Delamination mechanics of carbon nanotube micropillars," Applied Materials \& Interfaces, vol. 11, no. 38, pp. 35221-35227, 2019.

[4] T. Hajilounezhad, D. M. Ajiboye, and M. R. Maschmann, "Evaluating the forces generated during carbon nanotube forest growth and self-assembly," Materialia, vol. 7, p. 100371, 2019.
[5] T. Hajilounezhad and M. R. Maschmann, "Numerical investigation of internal forces during carbon nanotube forest selfassembly," in International Mechanical Engineering Congress and Exposition, Pittsburgh, PA, U.S.A, November 2018.

[6] T. Hajilounezhad, Z. A. Oraibi, R. Surya et al., Exploration of carbon nanotube forest synthesis-structure relationships using physics-based simulation and machine learning, IEEE, 2019.

[7] A. Rai, N. Subramanian, and A. Chattopadhyay, "Investigation of damage mechanisms in CNT nanocomposites using multiscale analysis," International Journal of Solids and Structures, vol. 120, pp. 115-124, 2017.

[8] G. V. Ramana, B. Padya, R. N. Kumar, K. V. P. Prabhakar, and P. K. Jain, "Mechanical properties of multi-walled carbon nanotube reinforced polymer nanocomposites," Indian Journal of Engineering \& Materials Science, vol. 17, pp. 331-337, 2010.

[9] J. R. I. Jayathilaka, D. D. P. D. Dehigaspitiya, S. T. Pathirana, and K. R. B. Herath, Failure mechanisms of carbon nanotube reinforced composites, Swinburne University of Technology, Washington State University, 2016.

[10] F. Taheri-Behrooz, M. Esmkhani, A. Yaghoobi-Chatroodi, and S. M. Ghoreishi, "Out-of-plane shear properties of glass/epoxy composites enhanced with carbon-nanofibers," Polymer Testing, vol. 55, pp. 278-286, 2016.

[11] M. M. Shokrieh, M. Esmkhani, and F. Taheri-Behrooz, "A novel model to predict the fatigue life of thermoplastic nanocomposites," Journal of Thermoplastic Composite Materials, vol. 28, no. 11, pp. 1496-1506, 2013.

[12] F. Taheri-Behrooz, M. Esmkhani, and A. Yaghoobi-Chatroodi, "Effect of testing procedure on the in-plane shear properties of CNF/glass/epoxy composites," Polymers and Polymer Composites, vol. 28, no. 3, pp. 159-169, 2020.

[13] M. M. Shokrieh, M. Esmkhani, F. Taheri-Behrooz, and A. R. Haghighatkhah, "Displacement-controlled flexural bending fatigue behavior of graphene/epoxy nanocomposites," Journal of Composite Materials, vol. 48, no. 24, pp. 2935-2944, 2013.

[14] G. Geng, X. Ma, H. Geng, and Y. Wu, "Effect of load on the thermal expansion behavior of T700 carbon fiber bundles," Polymers, vol. 10, no. 2, p. 152, 2018.

[15] J. J. Vilatela, R. Khare, and A. H. Windle, "The hierarchical structure and properties of multifunctional carbon nanotube fibre composites," Carbon, vol. 50, no. 3, pp. 1227-1234, 2012.

[16] K. Shirasu, A. Nakamura, G. Yamamoto et al., "Potential use of CNTs for production of zero thermal expansion coefficient composite materials: an experimental evaluation of axial thermal expansion coefficient of CNTs using a combination of thermal expansion and uniaxial tensile tests," Composites: Part A, vol. 95, pp. 152-160, 2017.

[17] H. G. Chae and S. Kumar, "Polymer/carbon nanotube composites-an overview," Indian Journal of Fibre \& Textile Research, vol. 31, pp. 29-40, 2006.

[18] A. Anvari, "Thermal life of carbon structures: from the earth to after the Titan," International Journal of Aerospace Engineering, vol. 2018, Article ID 7628614, 6 pages, 2018.

[19] T. S. U. Maheswari and P. H. Prasad, "Reliability of thermal strain and stresses in simple bars," IOSR Journal of Mathematics, vol. 5, no. 2, pp. 5-09, 2013.

[20] S. Y. Park, H. S. Choi, W. J. Choi, and H. Kwon, "Effect of vacuum thermal cyclic exposures on unidirectional carbon fiber/epoxy composites for low earth orbit space applications," 
Composites Part B: Engineering, vol. 43, no. 2, pp. 726-738, 2012.

[21] S. Yang and J. Qu, "Computing thermomechanical properties of crosslinked epoxy by molecular dynamic simulations," Polymer, vol. 53, no. 21, pp. 4806-4817, 2012.

[22] L. Deng, R. J. Young, I. A. Kinloch et al., "Coefficient of thermal expansion of carbon nanotubes measured by Raman spectroscopy," Applied Physics Letters, vol. 104, no. 5, article 051907, 2014.

[23] Z. H. Karadeniz, "A numerical study on the thermal expansion coefficient of fiber reinforced composite materials," Thesis, Graduate School of Natural and Applied Sciences, Dokuz Eylul University, Izmir, 2005.

[24] H. Mori, Y. Hirai, S. Ogata, S. Akita, and Y. Nakayama, "Chirality dependence of mechanical properties of single-walled carbon nanotubes under axial tensile strain," Japanese Journal of Applied Physics, vol. 44, no. 42, pp. L1307-L1309, 2005.

[25] Q. Lu and B. Bhattacharya, "Fracture resistance of zigzag single walled carbon nanotubes," Nanotechnology, vol. 17, no. 5, pp. 1323-1332, 2006.

[26] J. Wang and M. Gutierrez, "Stress-strain behaviour of carbon nanotubes under cyclic loading," Micro \& Nano Letters, vol. 2, no. 4, pp. 111-114, 2007.

[27] M. U. Kahaly and U. V. Waghmare, "Effect of curvature on structures and vibrations of zigzag carbon nanotubes: a firstprinciples study," Bulletin of Materials Science, vol. 31, no. 3, pp. 335-341, 2008.

[28] P. A. Gowri Sankar and K. Udhaya Kumar, "Mechanical and electrical properties of single walled carbon nanotubes: a computational study," European Journal of Scientific Research, vol. 60, no. 3, pp. 342-358, 2011.

[29] M. Zakeri and M. Shayanmehr, "On the mechanical properties of chiral carbon nanotubes," Journal of Ultrafine Grained and Nanostructured Materials, vol. 46, no. 1, pp. 1-9, 2013.

[30] G. Yarlagadda, G. Solasa, R. Boanapalli, P. Paladugu, and G. S. Babu, "Three-dimensional finite element (FE) model for armchair and zigzag type single-walled carbon nanotubes," International Journal of Scientific and Research Publications, vol. 3, no. 5, pp. 1-9, 2013.

[31] E. N. Ganesh, "Single walled and multi walled carbon nanotube structure, synthesis and applications," International Journal of Innovative Technology and Exploring Engineering (IJITEE), vol. 2, no. 4, pp. 311-320, 2013. 